Bull. Chem. Soc. Ethiop. 2019, 33(2), 229-241.

ISSN 1011-3924

(c) 2019 Chemical Society of Ethiopia and The Authors

Printed in Ethiopia

DOI: https://dx.doi.org/10.4314/bcse.v33i2.4

\title{
ADSORPTIVE REMOVAL OF NAPHTHALENE AND ANTHRACENE FROM AQUEOUS SOLUTION WITH ZINC AND COPPER-TEREPHTHALATE METAL- ORGANIC FRAMEWORKS
}

\author{
Hussein K. Okoro ${ }^{1 *}$, Adedibu C. Tella ${ }^{2}$, Oluwaseun Ajibola Ajibola ${ }^{1}$, Caliphs Zvinowanda ${ }^{3}$ and \\ J. Catherine Ngila $^{3}$ \\ ${ }^{1}$ Environmental-Analytical and Material Science Research Group, Department of Industrial \\ Chemistry, Faculty of Physical Sciences, P.M.B. 1515, University of Ilorin, Ilorin, Nigeria \\ ${ }^{2}$ Inorganic Chemistry and Synthesis Research Laboratory, Department of Chemistry, Faculty of \\ Physical Sciences, P.M.B. 1515, University of Ilorin, Ilorin, Nigeria \\ ${ }^{3}$ Analytical-Environmental and Membrane Nanotechnology Research Group, Department of \\ Applied Chemistry, University of Johannesburg, P.O. Box 17011, Doornfontein 2028, \\ Johannesburg, Republic of South Africa
}

(Received February 8, 2018; Revised April 10, 2019; Accepted May 10, 2019)

\begin{abstract}
This research employed the application of metal organic frameworks (MOFs) of zinc and copperbased materials in the removal of naphthalene and anthracene. Naphthalene and anthracene adsorption were investigated with both zinc-benzene-1,4-dicarboxylic (Zn-BDC) and copper-benzene-1,4-dicarboxylic (Cu-BDC) MOFs. Langmuir, Freundlich and Temkin adsorption isotherms were used to investigate the mechanisms of the data obtained. $\mathrm{Zn}-\mathrm{BDC}$ and $\mathrm{Cu}-\mathrm{BDC}$ MOFs were stable at a wide range of temperatures and they both exhibited appreciable desorption and regenerating ability. About $97 \%$ and 50\% removal were recorded for naphthalene and anthracene, respectively. The great success recorded for naphthalene has been attributed to the tighter fitting between the pores of the MOFs materials and naphthalene, as naphthalene molecules are less sterically hindered as compared to anthracene. Desorption and reusability result showed that both MOFs materials demonstrate high regeneration capacity, and the reuse of the materials proved effective for three batch adsorption process.
\end{abstract}

KEY WORDS: Naphthalene, Anthracene, Refluxing method, Regenerating ability, Adsorption

\section{INTRODUCTION}

Various methods and approach have been utilized in the removal of pollutants like polycyclic aromatic hydrocarbons, PAHs (fluorene, anthracene, naphthalene, etc.) and heavy metals from aqueous solutions [1-4]. These include solvent extraction, ion exchange filtration and membrane separation, reverse osmosis, chemical precipitation and coagulation. These methods are known for one limitation or the other, ranging from incomplete removal, high energy consumption, reagents cost, disposal of large volume of organic solvents and inefficiency when the metal concentrations are $10 \mathrm{mg} / \mathrm{L}$ [5].

PAHs enter the environment through various routes and they usually contain two or more compounds [6]. They are products of incomplete combustion ether through natural or manmade combustion sources during biological processes [7, 8]. Impacts of PAHs on human health are numerous as documented in the literatures, although, the effects of individual PAHs vary from each other, they are not the same. It has been confirmed that PAHs can pose carcinogenic and mutagenic effects on human and they are potent immunosuppressants [9]. Adsorption process is a promising alternative technique that is free from the shortcomings of the earlier techniques [10-12]. Adsorbents from natural or modified materials and synthetic origin are subject of recent research efforts. These adsorbents include activated carbon from agricultural products [13-15], clay and clay materials [16], oxides of iron [17], and metal organic frameworks, MOFs [18, 19].

*Corresponding author. okoroowo@yahoo.com

This work is licensed under the Creative Commons Attribution 4.0 International License 
The American Conference of Governmental Industrial Hygienist set the time-weighted average (TWA) to which occupational exposure to polycyclic aromatic hydrocarbons is deem save at $0.2 \mathrm{mg} / \mathrm{m}^{3}$ for a normal 8 hours' workday and 40 hours' workweek, and maximum contaminant level (MCL) in water was set at $0.0001-0.0004 \mathrm{mg} / \mathrm{L}$ with respect to the toxicity of the PAHs involved [20]. Naturally occurring anthracene and naphthalene usually result from incomplete combustion of organic matters such as tobacco smoke, coal, oil spillage, and refuse combustion [21]. PAHs are toxic and carcinogenic, the most notable effect of PAHs toxicity to humans is cancer. Many cases of lung, skin, and bladder cancers and developmental and reproductive toxicity have been reported [22].

Owing to their relatively low solubility in water and high affinity for particulate matter, they are not commonly dissolved in water but are appreciably adsorbed on particles in the water [23]. Metal organic frameworks (MOFs) are compounds consisting of metal ions or clusters coordinated to rigid organic molecules, they consist of two major components and these are: the central metal atom and the organic molecule which is known as the ligand. MOFs represent a promising new class of porous crystalline solids because they can be designed in such way as to have some of the largest pore volumes and highest surface areas known. In most cases, most MOFs exhibit permanent porosity and can be thermally stable to about $300{ }^{\circ} \mathrm{C}$ [24].

MOFs have cut the attention of many researchers over the years because of its significant advantages over other more traditional adsorbents. Some features of MOFs had made possible its synthetic modification of the ligand either before or even after the MOF has been prepared. In making MOF materials, the combination of metal centers and organic linkers is unlimited, making it possible for a wide variety of MOFs materials to be synthesized $[12,25,26]$. Consequently, with respect to zeolites, the structures and physical properties of MOFs can be controlled to a far greater extent.

MOFs are fabricated by connecting metal ions to organic linkers thereby forming a 3D porous framework and possessing various features, amongst are; surface area, uniform turnable size, flexible structure and functionalizing pores. For this study, the MOFs were chosen as a result of the void volumes and diameters of channels reported in ZnBDC and CuBDC which allows small to medium sized organic compounds both to diffuse through channels and to be covalently appended to reactive groups on the walls of the channels [12, 19, 27, 28]. The abovementioned characteristics make $\mathrm{CuBDC}$ and $\mathrm{ZnBDC}$ as potential candidates for application as adsorbents. Anthracene and naphthalene were chosen for this study owing to their toxicity problems, hydrophobic nature, similar dimension to that of MOFs with increasing dimensions thus making it suitable to study the surface interaction [11]. It is specifically these pore properties that allow MOFs to be potentially useful for volume specific applications such as adsorption, separation and purification. In the past, researchers have focused on developing the synthetic methodology necessary to synthesize MOFs but in the last decade to the present time, the focus of research on MOFs has shifted towards investigating the porous behavior of MOFs and their applications as efficient host materials [29]. One important area that is beginning to be explored is sorption of molecular guests and also to examine whether MOFs exhibit selectivity toward sorption of certain types of organic compounds and determine the origin of that selectivity.

The adsorption mechanism is $\mathrm{pH}$ dependent, the level of adsorption of the PAHs at acidic $\mathrm{pH}$ levels were low compared with that of the neutral and basic $\mathrm{pH}$. The PAHs being organic in nature attaches more readily with the adsorbent at neutral and basic $\mathrm{pH}$. This can be attributed to the fact that the MOFs being positively charged will be more repulsive to other species in acidic medium as compared to when it's in a neutral or basic medium which allows its surface to be able to attract other species. 
Mechanism of adsorption

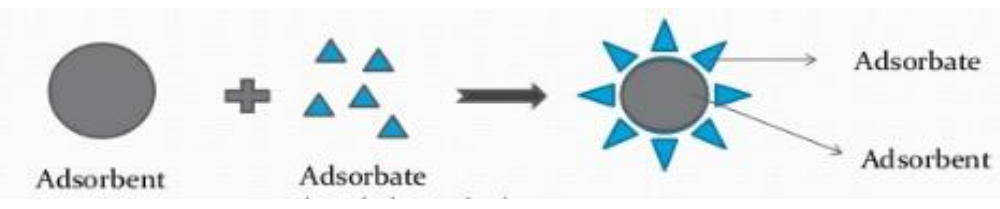

Scheme 1. Adsorption scheme.

EXPERIMENTAL

Chemical and reagents

In the research herein, zinc nitrate hexahydrate $\left[\mathrm{Zn}\left(\mathrm{NO}_{3}\right)_{2} \cdot 6 \mathrm{H}_{2} \mathrm{O}\right]$, copper nitrate trihydrate $\left[\mathrm{Cu}\left(\mathrm{NO}_{3}\right)_{2} \cdot 3 \mathrm{H}_{2} \mathrm{O}\right], 1$,4-benzene-1,4-dicarboxylic, $N, N$-dimethylformamide (DMF) and triethylamine (TEA) obtained from Sigma Aldrich. The chemicals were of analytical grade and were used without further purification.

\section{Instrumentation}

The instruments used in this study includes; atomic absorption spectrophotometry (AAS, model 210 VGP) to determine the concentration of the heavy metals solutions before and after adsorption. For the characterization study of the MOFs: the samples were observed by a scanning electron microscope (SEM, TESCAN from the Czech Republic) with a Vega 3Xmn software and SEM/EDX with INCA software. FT-IR (Spectrum 100; Serial No: 84460 from PerkinElmer) spectrometer in the attenuated total reflectance (ATR) mode (Universal ATR sampling Accessory, PerkinElmer) was used for the FTIR analysis. XRD analysis was performed with aid of X'Pert Philips X-ray Diffractometer and XRD, Rigagu Ultima IV from Japan. The Transmission electron microscopy (TEM) was carried out using TESCAN, Vega 3 XMU from Czech Republic.

Choice of MOFs and synthesis of MOFs

As a general requirement for sorption of guest molecules to occur, MOFs should have pore channels with dimension large enough to allow guest molecules to diffuse through them. In view of this, the MOFs that were used for this research work was selected due to their high porosity, appreciable surface area and high affinity for the guest molecules [31]. Scheme 1 shows the reaction scheme for the formation of ZnBDC and CuBDC. The copper-benzene-1,4dicarboxylic acid and zinc-benzene-1,4-dicarboxylic acid metal-organic frameworks were synthesized using the method described by Tella et al. [11].

\section{Effect of initial concentration of PAHs}

The adsorption of the PAHs (naphthalene and anthracene) by MOFs was studied over a concentration of $10-100 \mathrm{mg} / \mathrm{L}$. The effect of the initial concentration was studied by shaking $0.025 \mathrm{~g}$ of MOFs and $25 \mathrm{~mL}$ of the PAHs solutions in different flasks. The flasks were agitated for two hours with a constant speed of $265 \mathrm{rpm}$. After the adsorption step, the solution was separated from the adsorbent by centrifugation and the final concentration of the PAHs in the solutions was analyzed using UV-Visible spectrometer at the appropriate $\lambda_{\max }$ [32]. 
Effect of adsorbent dose

A $25 \mathrm{~mL}$ of the working solutions was put in different bottles. $0.01,0.02,0.03,0.04$ and $0.005 \mathrm{~g}$ of MOFs was added in each bottle. All the bottles were kept inside the shaker at $265 \mathrm{rpm}$ and 32 ${ }^{\circ} \mathrm{C}$ for $120 \mathrm{~min}$. The flasks were thereafter withdrawn from the shaker and the solution was separated from the adsorbent by centrifugation. The absorbance of all the solutions were then be measured and a graph of amount adsorbed (qe) vs. adsorbent dose $D$ was obtained.

$q_{\mathrm{e}}=\frac{(\mathrm{Co}-\mathrm{Ce}) V}{W}$

where, $q_{e}$ is the amount of PAHs adsorbed, $C_{0}$ is the initial PAHs concentration $(\mathrm{mg} / \mathrm{L})$ and $C_{e}$ is the final PAHs concentration $(\mathrm{mg} / \mathrm{L})$.

\section{Effect of contact time}

A working solution of $25 \mathrm{~mL}$ was measured in a conical flask. The mixture was then placed on a shaker at $265 \mathrm{rpm}$ and $32{ }^{\circ} \mathrm{C}$ for $30,60,90,120,150,180$ and 210 min after which the flasks were withdrawn from the shaker. The solution was separated from the adsorbents by centrifugation and the absorbance of the solutions was measured. A graph of $\mathrm{q}_{\mathrm{e}}$ vs contact time was obtained.

\section{Effect of temperature}

A mass of $0.025 \mathrm{~g}$ of MOFs was weighted and introduced into $25 \mathrm{~mL}$ of the working solutions in different bottles. The mixture was placed in a shaker at a speed of $265 \mathrm{rpm}$ for $120 \mathrm{~min}$ over the temperature range of $32-70{ }^{\circ} \mathrm{C}$. The bottles were withdrawn from the shaker, the solution separated from the adsorbents by centrifugation and the absorbance of the solutions was measured. A graph of quantity adsorbed $\mathrm{q}_{\mathrm{e}}$ vs temperature ( $\mathrm{t}$ ) was plotted [33].

\section{Effect of initial $\mathrm{pH}$}

As in the preceding paragraph, a mass of $0.025 \mathrm{~g}$ of the MOFs was weighed and added into 25 $\mathrm{mL}$ solution of PAHs (naphthalene and anthracene). The solution $\mathrm{pH}$ was adjusted to a desired value within the range of 2, 5, 7, 9 and 12 by the addition of $0.01 \mathrm{M} \mathrm{HCl}$ or $0.01 \mathrm{M} \mathrm{NaOH}$. The mixture was agitated at the speed of $265 \mathrm{rpm}$ for $120 \mathrm{~min}$. After the adsorption step, the solution was separated from the adsorbents by centrifugation and the final concentration of the PAHs in the solution was analyzed using UV-Vis spectrometer.

\section{Regeneration and desorption studies}

The normal sorption procedure was carried out using $0.025 \mathrm{~g}$ of MOFs material in $25 \mathrm{~mL}$ of PAHs solutions the mixture was shaken for $120 \mathrm{~min}$ and adsorbent was separated from the solution by centrifugation, the solution was analyzed for PAHs while the residue was used for desorption experiment as follows:

A $25 \mathrm{~mL}$ of different concentrations of $\mathrm{HCl}(0.1,0.2,0.5$ and $1.0 \mathrm{M})$ was added to the residues in different conical flasks, each mixture was shaken for $120 \mathrm{~min}$ and then separated by centrifugation. The filtrate was analyzed for the amount of PAHs released back into the solution. This sorption and desorption processes was repeated on the same sample for three more times. The quantity sorbed or desorbed was then calculated using the formula:

$q_{\mathrm{e}}=\frac{(\mathrm{Co}-\mathrm{Ce}) V}{W}$

A graph of the quantity desorbed was plotted against the steps of the desorption process for the different ionic strengths [34].

Bull. Chem. Soc. Ethiop. 2019, 33(2) 


\section{RESULTS}

\section{Sorption results}

This study investigated the removal efficiency of PAHs from laboratory samples, comparison of the effectiveness of PAHs; naphthalene and anthracene; removal employing two different metalorganic frameworks (MOFs); $\mathrm{Zn}-\mathrm{BDC}$ and $\mathrm{Cu}-\mathrm{BDC}$. The optimum concentration, contact time, $\mathrm{pH}$, adsorbent dose and temperature that favors the removal of naphthalene and anthracene were determined. Finally, desorption and regenerating ability of the utilized MOFs were carried out.

The two adsorbates had the optimum adsorption between 80 and $100 \mathrm{mg} / \mathrm{L}$ (Figure 1A). However, naphthalene had the higher adsorption when compared to the adsorption of anthracene. As the concentration is increased the adsorption characteristics also increases. Figure 1A, 1B shows the effect of adsorbents dosage and the effects of initial concentration on adsorbate using $\mathrm{Cu}-\mathrm{BDC}$ and similar trend to Zn-BDC were observed [35]. Naphthalene had higher adsorption when compared with anthracene. Higher adsorption was observed at $210 \mathrm{~min}$ for naphthalene, while anthracene had the highest adsorption at $120 \mathrm{~min}$. Figure $1 \mathrm{C}$ shows the effect of time on adsorbate using Cu-BDC. Similar trends as Zn-BDC were observed.

The temperature effect on adsorption shows a similar trend with naphthalene. Figure 1D shows a steady increase in sorption of naphthalene within the range of 32 and $60{ }^{\circ} \mathrm{C}$. Naphthalene recorded a higher adsorption when compared with anthracene. However, the adsorption of naphthalene increased at the $\mathrm{pH}$ of 2 and decreases as the $\mathrm{pH}$ increases. The adsorption of anthracene was higher at $\mathrm{pH}$ of 7 and decreases as $\mathrm{pH}$ increases. Figure 1E shows the effect of $\mathrm{pH}$ on adsorbate using $\mathrm{Cu}-\mathrm{BDC}$. Naphthalene had the higher adsorption when compared with anthracene. However, the adsorption of naphthalene and anthracene was high at the $\mathrm{pH}$ of 7 and decreases as the $\mathrm{pH}$ increases.

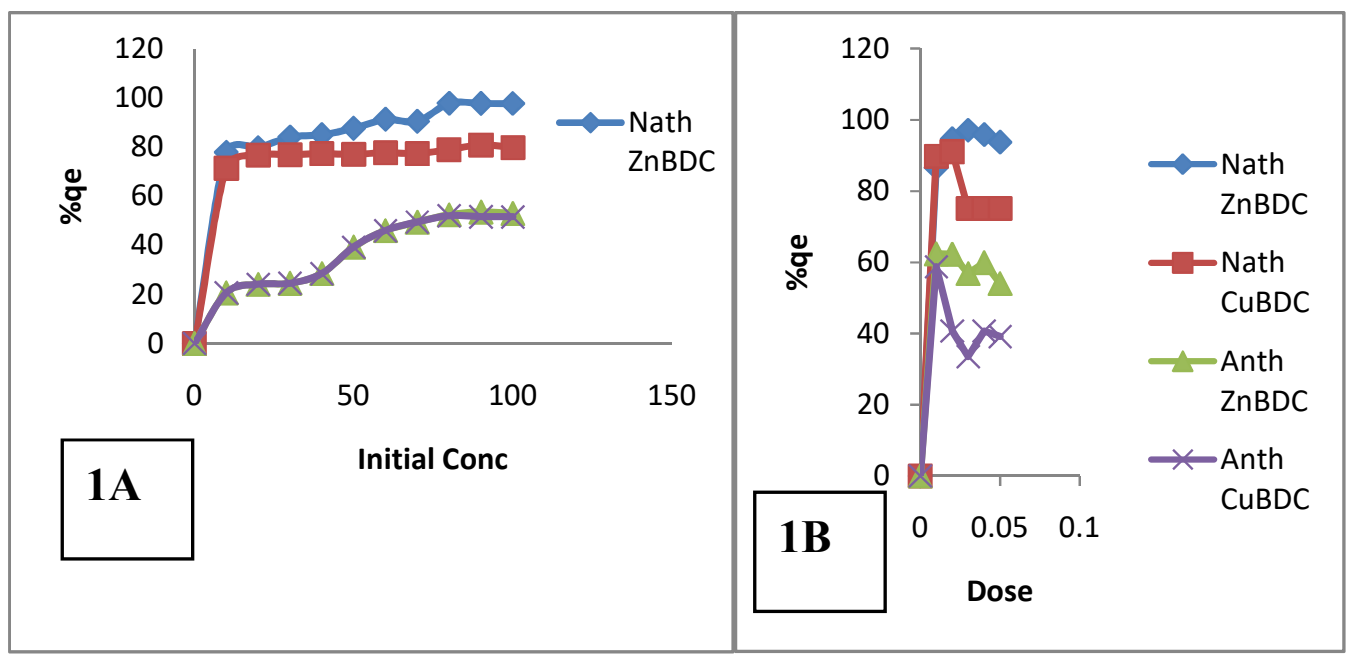



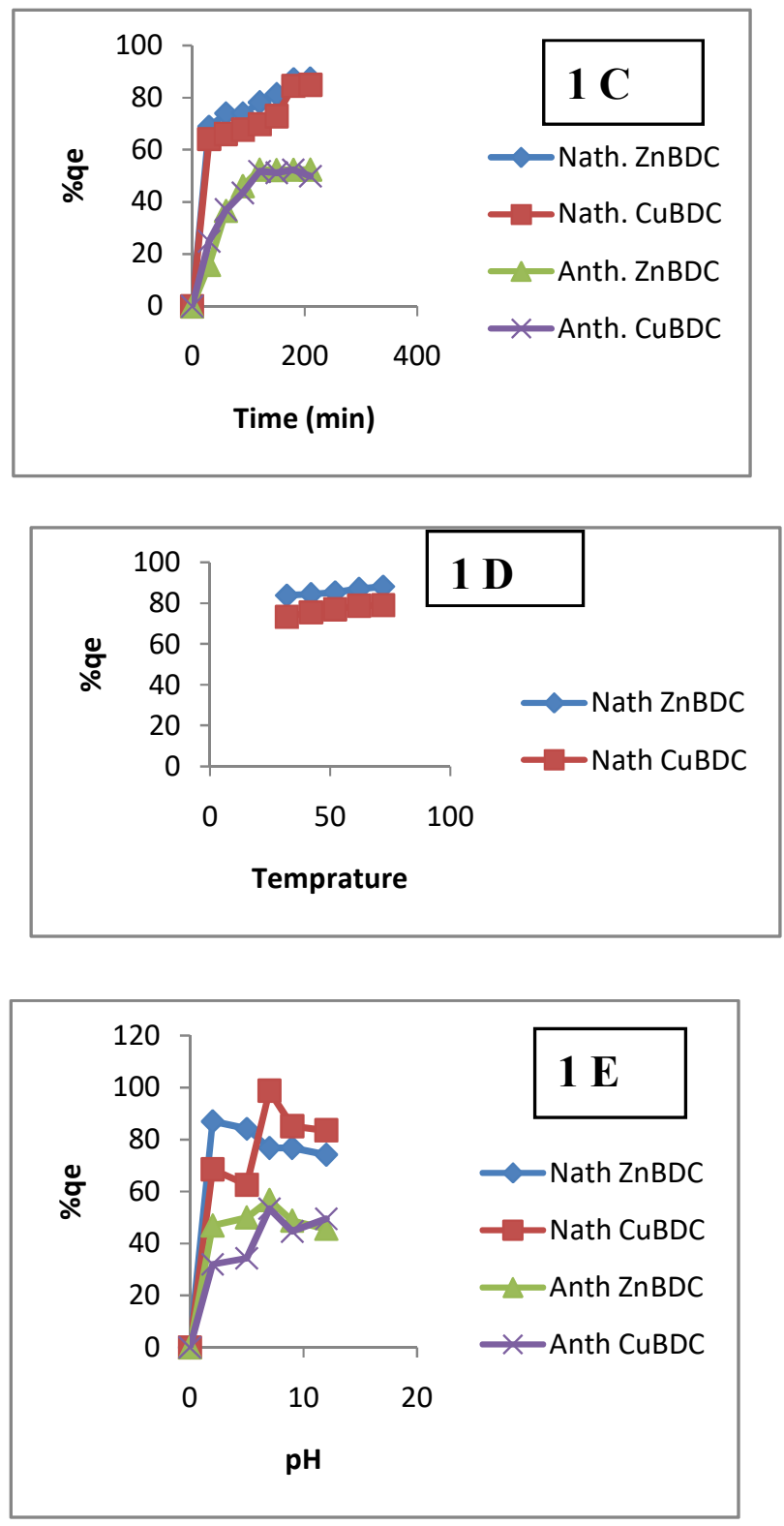

Figure 1. A = Effect of initial concentration on adsorbate using Zn-BDC and CuBDC MOFs. B $=$ Effect of adsorbent dosage on the removal of naphthalene and anthracene from solution using ZnBDC and CuBDC MOFs. $\mathrm{C}=$ Effect of time on adsorbate using Zn$\mathrm{BDC}$ and CuBDC MOFs. D = Effect of varying temperature on adsorbate using Zn$\mathrm{BDC}$ and $\mathrm{Cu} \mathrm{BDC}$ MOFs. $\mathrm{E}=$ Effect of varying $\mathrm{pH}$ on adsorbate using $\mathrm{Zn}-\mathrm{BDC}$ and $\mathrm{Cu} \mathrm{BDC}$. 
Adsorption isotherm

Langmuir

The data obtained from the adsorption process for naphthalene and anthracene with $\mathrm{Zn}$-BDC and $\mathrm{Cu}$-BDC MOFs over the concentration range of $10-100 \mathrm{mg} / \mathrm{L}$ at $32{ }^{\circ} \mathrm{C}$ has been correlated with the Langmuir isotherm. A graph of $\mathrm{C}_{\mathrm{e}} / \mathrm{q}_{\mathrm{e}}$ versus $\mathrm{C}_{\mathrm{e}}$ was plotted (Figure 2), and a linear plot was obtained.

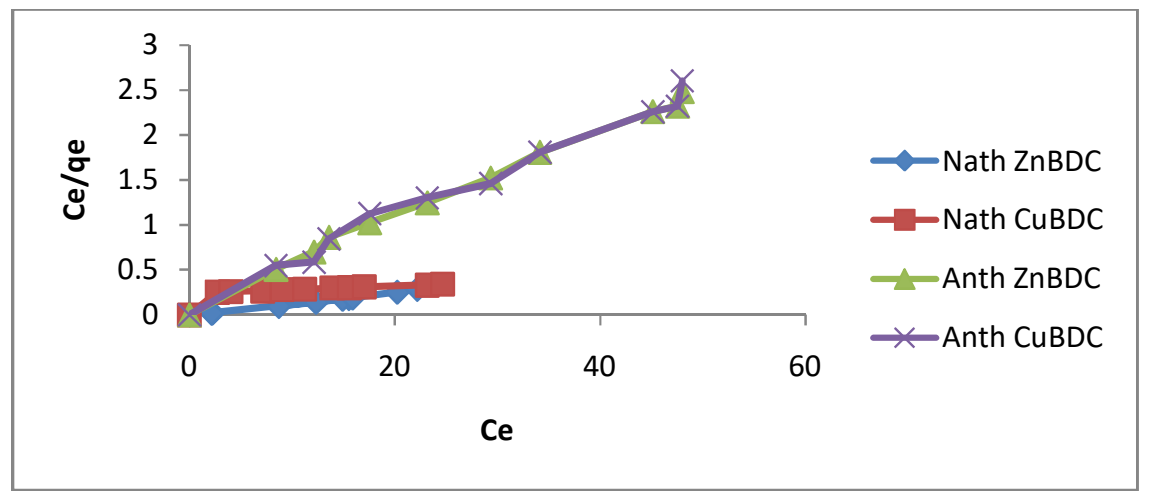

Figure 2. Plot of Langmuir adsorption isotherm, where $\mathrm{q}_{\max }$ is the Langmuir constant related to monolayer adsorption capacity, $\mathrm{K}_{\mathrm{L}}$ is the Langmuir constant related to affinity of adsorbent towards the adsorbate and $\mathrm{R}^{2}$ is regression coefficient.

Temkin

The data obtained from the adsorption process for naphthalene and anthracene with Zn-BDC and $\mathrm{Cu}-\mathrm{BDC}$ MOFs over the concentration range of $10-100 \mathrm{mg} / \mathrm{L}$ at $32{ }^{\circ} \mathrm{C}$ has been correlated with Temkin isotherm. A graph of $\mathrm{q}_{\mathrm{e}}$ versus $\ln$ Ce was plotted and a linear plot was obtained.

\section{Freundlich}

The data obtained from the adsorption process for naphthalene and anthracene with Zn-BDC and $\mathrm{Cu}-\mathrm{BDC}$ MOFs over the concentration range of $10-100 \mathrm{mg} / \mathrm{L}$ at $32{ }^{\circ} \mathrm{C}$ has been correlated with Freundlich isotherm. A graph of $\log \mathrm{q}_{\mathrm{e}}$ versus $\log \mathrm{C}_{\mathrm{e}}$ was plotted and a linear plot was obtained.

From the regression coefficient values $\left(\mathrm{R}^{2}\right)$ as depicted on Table 1 , the adsorption data obtained from this study fitted best into the Langmuir adsorption isotherm. This is indicative of the fact that the adsorption process is more of monolayer sorption than heterogeneous energy distribution.

Table 1. Comparison of the $\mathrm{R}^{2}$ values obtained for the adsorption process.

\begin{tabular}{|c|c|c|c|c|}
\hline Parameters & \multicolumn{2}{|c|}{ Naphthalene } & \multicolumn{2}{c|}{ Anthracene } \\
\hline MOFs & Zn-BDC & Cu-BDC & Zn-BDC & Cu-BDC \\
\hline Langmuir & 0.9957 & 0.9937 & 0.9953 & 0.9817 \\
\hline Freundlich & 0.9673 & 0.9633 & 0.9083 & 0.9201 \\
\hline Temkin & 0.9353 & 0.9372 & 0.943 & 0.9476 \\
\hline
\end{tabular}

Bull. Chem. Soc. Ethiop. 2019, 33(2) 


\section{Kinetic model}

The adsorption process was carried out at different contact time to determine the amount of anthracene and naphthalene adsorbed by the $\mathrm{Cu}-\mathrm{BDC}$ and $\mathrm{Zn}-\mathrm{BDC}$ MOFs. The data obtained was subjected to the pseudo first order and pseudo second order kinetic models.

\section{Pseudo first order kinetic model}

The adsorption data were tested with the pseudo first order kinetic model which is represented by the equation: $\log \left[\mathrm{q}_{\mathrm{e}}-\mathrm{qt}\right]=\log \left[\mathrm{q}_{\mathrm{e}}\right]-\left[\mathrm{k}_{1} / 2.303\right] \mathrm{t}$. A plot $\log \left(\mathrm{q}_{\mathrm{e}}-\mathrm{qt}\right)$ against time was done and the value of the first order kinetic constant $\left(\mathrm{k}_{1}\right)$ was calculated (Table 2) [36].

Table 2. The pseudo first order kinetic model parameters and the value obtained for the sorption of naphthalene and anthracene by $\mathrm{Zn}-\mathrm{BDC}$ and $\mathrm{Cu}-\mathrm{BDC}$.

\begin{tabular}{|c|c|c|c|c|}
\hline Parameters & \multicolumn{2}{|c|}{ Naphthalene } & \multicolumn{2}{c|}{ Anthracene } \\
\hline MOFs & Zn-BDC & Cu-BDC & Zn-BDC & Cu-BDC \\
\hline $\mathrm{R}^{2}$ & 0.8913 & 0.9817 & 0.9131 & 0.9791 \\
\hline $\mathrm{q}_{\mathrm{e}(\mathrm{exp})}$ & 87.2 & 84.8 & 52.19 & 52.36 \\
\hline $\mathrm{q}_{\mathrm{e}(\mathrm{calc})}$ & 40 & 29.70 & 38.69 & 33.95 \\
\hline $\mathrm{K}_{1}$ & 0.0029 & 0.000608 & 0.003 & 0.0024 \\
\hline
\end{tabular}

The regression coefficient values $\left(\mathrm{R}^{2}\right)$ show that applicability of the kinetic model to the adsorption process. The values obtained (Table 2) shows that the pseudo first order kinetic model is not suitable for the sorption of naphthalene and anthracene by $\mathrm{Zn}-\mathrm{BDC}$ and $\mathrm{Cu}-\mathrm{BDC}$.

\section{Pseudo second order kinetic model}

The adsorption data were tested with the pseudo second order kinetic model which is represented by the equation: $\mathrm{t} / \mathrm{qt}=1 / \mathrm{k}_{2} \mathrm{q}_{\mathrm{e}}{ }^{2}+\left[1 / \mathrm{q}_{\mathrm{e}}\right] \mathrm{t}$. A plot $\mathrm{t} / \mathrm{qt}$ against time was done and the values of the second order kinetic constant $\left(\mathrm{k}_{2}\right)$ was calculated.

Table 3. The pseudo second order kinetic model parameters and the value obtained for the sorption of naphthalene and anthracene by $\mathrm{Zn}-\mathrm{BDC}$ and $\mathrm{Cu}-\mathrm{BDC}$.

\begin{tabular}{|c|c|c|c|c|}
\hline Parameters & \multicolumn{2}{|c|}{ Naphthalene } & \multicolumn{2}{c|}{ Anthracene } \\
\hline MOFs & Zn-BDC & Cu-BDC & Zn-BDC & Cu-BDC \\
\hline $\mathrm{R}^{2}$ & 0.9933 & 0.9731 & 0.9776 & 0.9811 \\
\hline $\mathrm{q}_{\text {e(exp) }}$ & 87.2 & 84.8 & 52.19 & 52.36 \\
\hline $\mathrm{q}_{\mathrm{e}(\mathrm{cal})}$ & 92.59 & 90.9 & 67.11 & 62.11 \\
\hline $\mathrm{K}_{2}$ & 0.055 & 0.041 & 0.204 & 0.026 \\
\hline
\end{tabular}

The regression coefficient values $\left(\mathrm{R}^{2}\right)$ show that applicability of the kinetic model to the adsorption process. The values obtained shows that the pseudo second order kinetic model (Table 3) is suitable for the sorption of naphthalene and anthracene by $\mathrm{Zn}-\mathrm{BDC}$ and $\mathrm{Cu}-\mathrm{BDC}$.

\section{Thermodynamics studies}

The adsorption process was carried out at different temperatures to ascertain the temperature effect on the amount of naphthalene and anthracene adsorbed by the $\mathrm{Cu}-\mathrm{BDC}$ and $\mathrm{Zn}-\mathrm{BDC}$ MOFs (Table 4 and 5). The values of $\Delta \mathrm{H}$ and $\Delta \mathrm{s}$ were calculated as follows: 
$\ln K=\frac{-\Delta H}{R} \times \frac{1}{T}+\frac{\Delta S}{R}$

where slope $=-\Delta \mathrm{H} / \mathrm{R}$ and intercept $=-\Delta \mathrm{S} / \mathrm{R}$.

$\Delta G=\Delta H-T \Delta \mathrm{S}$

where $\mathrm{R}=$ gas constant, $\Delta \mathrm{S}=$ entropy, $\Delta \mathrm{H}=$ enthalpy and $\mathrm{T}=$ temprature.

Table 4. Thermodynamic parameters and the value obtained for the sorption of naphthalene by Zn-BDC and $\mathrm{Cu}-\mathrm{BDC}$.

\begin{tabular}{|c|c|c|c|c|c|c|}
\hline \multirow{2}{*}{$\begin{array}{c}\text { Temperature } \\
(\mathrm{K})\end{array}$} & \multicolumn{5}{|c|}{ Zn-BDC } & \multicolumn{3}{c|}{$\mathrm{Cu}-\mathrm{BDC}$} \\
\cline { 2 - 7 } & $\Delta \mathrm{G}(\mathrm{kJ} / \mathrm{mol})$ & $\Delta \mathrm{H}(\mathrm{kJ} / \mathrm{mol})$ & $\Delta \mathrm{S}(\mathrm{kJ} / \mathrm{mol})$ & $\Delta \mathrm{G}(\mathrm{kJ} / \mathrm{mol})$ & $\Delta \mathrm{H}(\mathrm{kJ} / \mathrm{mol})$ & $\Delta \mathrm{S}(\mathrm{kJ} / \mathrm{mol})$ \\
\hline 305 & -0.00938 & +0.00249 & 0.03076 & -1.695 & -251.5 & +4.734 \\
\hline 315 & -0.00968 & & & -1.743 & & \\
\hline 325 & -0.00999 & & & -1.790 & & \\
\hline 335 & -0.0103 & & & -1.837 & & \\
\hline 345 & -0.0106 & & & -1.885 & & \\
\hline
\end{tabular}

Table 5. Thermodynamic parameters and the value obtained for the sorption of anthracene by Zn-BDC and $\mathrm{Cu}-\mathrm{BDC}$.

\begin{tabular}{|c|c|c|c|c|c|c|}
\hline \multirow{2}{*}{$\begin{array}{c}\text { Temperature } \\
(\mathrm{K})\end{array}$} & \multicolumn{5}{|c|}{ Anthracene } \\
\cline { 2 - 7 } & $\Delta \mathrm{G}(\mathrm{kJ} / \mathrm{mol})$ & $\Delta \mathrm{H}(\mathrm{kJ} / \mathrm{mol})$ & $\Delta \mathrm{S}(\mathrm{kJ} / \mathrm{mol})$ & $\Delta \mathrm{G}(\mathrm{kJ} / \mathrm{mol})$ & $\Delta \mathrm{H}(\mathrm{kJ} / \mathrm{mol})$ & $\Delta \mathrm{S}(\mathrm{kJ} / \mathrm{mol})$ \\
\hline 305 & -0.0109 & +0.0003325 & +0.03575 & -3.348 & +378.1 & +12.22 \\
\hline 313 & -0.0111 & & & -3.345 & & \\
\hline 323 & -0.0115 & & & -3.568 & & \\
\hline 333 & -0.0119 & & & -3.690 & & \\
\hline
\end{tabular}

\section{Re-usability test}

Both $\mathrm{Zn}-\mathrm{BDC}$ and $\mathrm{Cu}-\mathrm{BDC}$ demonstrated great stability for successive batch sorption processes (Table 6). This suggests that the MOFs have excellent recovery and re-usability capacity in most cases. The trend shows that the sorption capacity of the MOFs decreases with each batch process. The sorption capacity was observed to have drastically reduced after the third reuse. The trend can rather be attributed to pore channels being occupied by foreign molecules other than structural collapse of the MOFs materials [37].

Table 6. Reusability of MOFs for batch adsorption processes.

\begin{tabular}{|c|c|c|c|c|}
\hline Parameter & \multicolumn{2}{|c|}{ Naphthalene } & \multicolumn{2}{c|}{ Anthracene } \\
\hline MOFs & Zn-BDC & Cu-BDC & Zn-BDC & Cu-BDC \\
\hline 1 & $87.56 \%$ & $84.25 \%$ & $49.95 \%$ & $52.01 \%$ \\
\hline 2 & $87.25 \%$ & $75.35 \%$ & $49.24 \%$ & $50.98 \%$ \\
\hline 3 & $84.25 \%$ & $75.15 \%$ & $38.13 \%$ & $51.18 \%$ \\
\hline
\end{tabular}

Table 7. Comparisons of adsorption capacities with literature.

\begin{tabular}{|c|c|c|c|}
\hline Adsorbate & Adsorbents & Qm (mg. . $\left.^{-1}\right)$ & References \\
\hline Anthracene & ZnBDC, CuBDC & 500 & This study \\
\hline Naphthalene & ZnBDC, CuBDC & 970 & This study \\
\hline Anthracene & ZnBDC & 22.73 & {$[11]$} \\
\hline Anthracene & NiBDC MOF & 330 & {$[38]$} \\
\hline Phenanthrene & NiBDC MOF & 910 & {$[38]$} \\
\hline
\end{tabular}

Bull. Chem. Soc. Ethiop. 2019, 33(2) 


\section{DISCUSSION}

\section{Effect of initial PAHs concentration}

The sorption performance of the $\mathrm{Zn}$-BDC and $\mathrm{Cu}-\mathrm{BDC}$ MOFs was examined by varying the initial concentration of PAHs over the ranges of $10 \mathrm{mg} / \mathrm{L}$. All other parameters were kept constant at $\mathrm{pH}$ of 7 , temperature of $32{ }^{\circ} \mathrm{C}, 0.025 \mathrm{~g}$ of adsorbent and $180 \mathrm{~min}$ contact time. The adsorption of the PAHs was observed to increase generally with increase in the concentration of the PAHs initially until a fairly constant adsorption of the PAHs with further increase in the concentration of PAHs was reached (Figure 1A). Compared to adsorption of anthracene $(50 \%)$, the adsorption of naphthalene (97\%) proved more favorable with both $\mathrm{Zn}$-BDC and Cu-BDC MOFs. The adsorption capacities values were compared with what obtained in the literature (Table 7), the results obtained in this study shows that the synthesized MOFs is a good potential adsorbent for removal of anthracene and naphthalene, respectively. This observation can be accounted for by the fact that the tighter fitting between the pores of the MOFs materials and the simpler (double rings) and smaller molecules of naphthalene compared to anthracene.

Figure 1B shows the effect of adsorbent dose on adsorbate using Zn-BDC and CuBDC. For ZnBDC, Naphthalene recorded the higher adsorption when compared with anthracene. However, the adsorption of naphthalene increases as the adsorbent increases up to $0.03 \mathrm{~g}$ and decreases as the adsorbent dose was further increased. In the case anthracene, the adsorption decreased as the adsorbent dose increased from $0.01 \mathrm{~g}$ to $0.05 \mathrm{~g}$. Generally, anthracene showed a more steeply decrease in comparison with naphthalene which showed a relatively constant behavior from $0.02 \mathrm{~g}$ to $0.05 \mathrm{~g}$ for $\mathrm{Cu}-\mathrm{BDC}$. Naphthalene recorded a higher adsorption when compared with anthracene. However, the adsorption of naphthalene increased slightly as the adsorbent dose increases up to $0.025 \mathrm{~g}$ and decreases as the adsorbent dose was further increased to $0.05 \mathrm{~g}$. Anthracene was better adsorbed with $0.01 \mathrm{~g} \mathrm{Cu}-\mathrm{BDC}$, as the adsorbent dose was increased the adsorption characteristics decreases. This is similar to the reported work [35].

\section{Effect of contact time}

Effect of contact time was studied to measure the rate at which the PAHs are binds and removed from the surface of the MOFs. The effect of contact time for naphthalene and anthracene were studied at $\mathrm{pH} 7$, temperature of $32{ }^{\circ} \mathrm{C}, 0.025 \mathrm{~g}$ of the adsorbent and a concentration of $100 \mathrm{mg} / \mathrm{L}$. The contact time was varied in the range 30,60, 90, 120, 150180 and $210 \mathrm{~min}$. An initial increase in the amount of PAHs adsorbed was observed with increase in time until an equilibrium characterized by a slight decrease was reached. Figure $1 \mathrm{C}$ show the effect of the contact time on PAHs and the MOFs. This is in-line with the reported work [36]. Naphthalene had higher adsorption when compared with anthracene. Higher adsorption was observed at 210 minutes for naphthalene, while anthracene had the highest adsorption at $120 \mathrm{~min}$.

\section{Effect of temperature}

To determine whether the adsorption process is exothermic or endothermic in nature, the adsorption capabilities of the MOFs was studied over a range of temperature. The temperature range considered for this study is $32,42,52,62$ and $72^{\circ} \mathrm{C}$ respectively at a $\mathrm{pH}$ of $7,0.025 \mathrm{~g}$ of adsorbent, 100 ppm PAHs (naphthalene only) concentration and 180 minutes' contact time. A slight and steady increase in the sorption capacities of the two MOFs was observed throughout the temperature range studied for this work (Figure 1D). This is indicative of the fact that the two MOFs are very stable over this temperature range. The slight increase in the sorption capacity of the MOFs with increasing temperature can be attributed to lower bonding energy required for bond formation between the adsorbent and the adsorbate. This agrees with the work done by [35]. 
Effect of $p H$

$\mathrm{pH}$ is one of the major factors affecting the adsorptive capabilities of PAHs. The adsorption characteristics of naphthalene and anthracene were studied at various $\mathrm{pH}$ values ranging from 2 , $5,7,9$ and 12 at a temperature of $32{ }^{\circ} \mathrm{C}, 0.025 \mathrm{~g}$ of adsorbent, $100 \mathrm{mg} / \mathrm{L}$ of PAHs concentration and 180 min contact time. The result shows that the optimum $\mathrm{pH}$ for adsorption of PAHs by $\mathrm{Zn}$ $\mathrm{BDC}$ MOFs is $\mathrm{pH} 2$ for naphthalene and $\mathrm{pH} 7$ for anthracene thereby showing that naphthalene was optimally adsorbed (Figure 1E). However, for $\mathrm{Cu}-\mathrm{BDC}$ MOFs the values obtained shows that naphthalene was optimally adsorbed at a $\mathrm{pH}$ of 9 and anthracene at a $\mathrm{pH}$ of 12 . The better performance of the MOFs at basic $\mathrm{pH}$ may be explained on the basis of a decrease in the competition between proton $\left(\mathrm{H}^{+}\right)$and the positively charged surfaces as it decreases the positive charge.

\section{Isotherms}

The regression coefficient values $\left(\mathrm{R}^{2}\right)$ show the applicability of the isotherm to the adsorption process. The values obtained shows that the Langmuir isotherm is suitable for the adsorbents studied.

\section{CONCLUSION}

Required MOFs; zinc and copper MOFs of benzene-1,4-carboxylic acid were applied in this study. The materials stability was credible over a wide temperature range and used in the removal of naphthalene and anthracene. The sorption process was found to be more favorable with both $\mathrm{Zn}-\mathrm{BDC}$ and $\mathrm{Cu}-\mathrm{BDC}$ MOFs. Based on the $\mathrm{R}^{2}$ values, the investigational data correlated reasonably well by the Langmuir, Freundlich and Temkim adsorption isotherms and the isotherm parameters were calculated. The values of $\Delta \mathrm{H}^{\circ}, \Delta \mathrm{S}^{\circ}$ and $\Delta \mathrm{G}^{\circ}$ results shows that the MOFs employed have a considerable potential as an adsorbent for the removal of PAHs pollutants.

\section{ACKNOWLEDGMENTS}

The authors, H.K. Okoro and J.C. Ngila thank UJ Global Excellence and Stature Scholarship for the running cost paid through the Water Research Commission (WRC) Project No. K5/2365. They are also grateful to the Royal Society of Chemistry for the award of the 2013 research fund to them to facilitate the study. The authors also thank the University of Ilorin, Ilorin, Nigeria and the University of Johannesburg, South Africa, for making available their respective library database and laboratory facilities.

\section{REFERENCES}

1. Omar, W.; Al-Itawi, H. Removal of $\mathrm{Pb}^{2+}$ ions from aqueous solutions by adsorption on kaolinite clay. Am. J. Appl. Sci. 2007, 4, 502-507.

2. Molinari, R.; Arguiro, P.; Poerio, T. Comparison of polyethyleneimine, polyacrylic acid, and poly(dimethylamine-coepichlorohydrin-coethylenediamine) in $\mathrm{Cu}^{2+}$ removal from wastewaters by polymer assisted ultrafiltration. Desalination 2004, 162, 217-228.

3. Gode, F., Pehlivan, E. Removal of chromium III from aqueous solutions using Lewatit S 100: The effect of $\mathrm{pH}$, time, metal concentration and temperature. J. Hazard. Mater. 2006, 136, 330-337.

4. Kadirvelu, K.; Namasivayam, C. Activated carbon from coconut coirpith as metal adsorbent: Adsorption of Cd(II) from aqueous solutions. Adv. Environ. Res. 2003, 7, 471-478.

5. Amer, N.W.; Khalili, F.I.; Awwad, A.M. Adsorption of lead, zinc and cadmium ions on polyphosphate-modified kaolinite clay. J. Environ. Chem. Ecotoxicol. 2010, 2, 001-008. 
6. Abdel-Shafy, H.I.; Mansour, SM. A review on polycyclic aromatichydrocarbons: Source, environmental impact, effect on human health and remediation. Egypt. J. Pet. 2016, 25, 107-123.

7. Baklanov, A.; Hanninen, O.; Slørdal, L.H.; Kukkonen, J.; Bjergene, N.; Fay, B. Atmos. Chem. Phys. 2007, 7, 855-874.

8. Olabemiwo, O.M.; Adediran, G.O.; Adekola, F.A.; Olajire, A.A. Aliphatic and polycyclic aromatic hydrocarbons profiles of photo modified natural bitumen of Agbabu, Southwestern Nigeria. Bull Chem. Soc. Ethiop. 2010, 24, 461-466.

9. Canadian Council of Ministers of the Environment. Canadian soil quality guidelines for the protection ofenvironmental and human health: Carcinogenic and Other PAHs. In: Canadian environmental quality guidelines, 1999, Canadian Council of Ministers of the Environment: Winnipeg; 2010.

10. Mohamed, N.R. Adsorption technique for the removal of organic pollutants from water and wastewater, organic pollutants - monitoring, risk and treatment. IntechOpen 2013. DOI: $10.5772 / 54048$.

11. Tella, A.C.; Nwosu, F.O.; Elaigwu, S.E.; Ezeh, C.P.; Adimula, V.O. Removal of anthracene from solution using $\left[\mathrm{Cu}(\mathrm{INA})_{2}\right]$ metal - organic frame work synthesized by a sol solvent free method. Nig. J. Mat. Sci. Eng. 2016, 7, 26-34.

12. Okoro, H.K.; Ayika, S.O.; Ngila, J.C.; Tella, A.C. Rising profile on the use of metal-organic frameworks (MOFs) for the removal of heavy metals from the environment: An overview. Appl. Water Sci. 2018, 8, 169. DOI: 10.1007/s13201-018-0818-3.

13. Su, W.; Zhou, L.; Zhou, Y. Preparation of microporous activated carbon from raw coconut shell by two-step procedure. Chin. J. Chem. Eng. 2006, 14, 266-269.

14. Babarinde, N.A.; Babalola, J.O.; Sanni, R.A. Biosorption of lead ions from aqueous solution by maize leaf. Int. J. Phys. Sci. 2006, 1, 23-26.

15. Pehlivan, E.; Altun, T.; Paravici, S. Utilization of barley straws as biosorbents for $\mathrm{Cu}^{2+}$ and $\mathrm{Pb}^{2+}$ ions. J. Hazard. Mater. 2009, 164, 982-986.

16. Chip, A.; Lena, M. Concentration, $\mathrm{pH}$, and surface charge effects on cadmium and lead sorption in three tropical soils. J. Environ. Qual. 2002, 31, 581-589.

17. Abdus-Salam, N.; Adekola, F.A. Comparative dissolution of natural goethite samples in $\mathrm{HCl}$ and $\mathrm{HNO}_{3}$. JASEM 2006, 10, 11-17.

18. Mondloch, J.E.; Bury, W.; Fairen-Jimenez, D.; Kwon, S.; DeMarco, E.J.; Weston, M.H.; Sarjeant, A.A.; Nguyen, S.T.; Stair, P.C.; Snurr, R.Q.; Farha, O.K.; Hupp, J.T. Vapor-phase metalation by atomic layer deposition in a metal-organic framework. J. Am. Chem. Soc. 2013, 135, 10294-10297.

19. Okoro, H.K.; Ayika, S.O.; Tella, A.C.; Ngila, J.C. Metal-organic frameworks (MOFs) derived from carboxylate ligand as potential materials for remediation of $\mathrm{Cd}$ (II) and $\mathrm{Pb}$ (II) from aqueous solution. J. Turk. Chem. Soc. 2019, 6, 165-176.

20. Agency for Toxic Substance and Disease Registry (ATSDR), Public Health Statement August 1995. Accessed 12-09, 2010.

21. Edvinas, K.; Dainius, M.; Ruta, S.; Darius, C.; Tedas, P.; Violeta, K.; Inga, S.; Linas, K.; Characterization of particulate and vapor phase polycyclic aromatic hydrocarbons in indoor and outdoor air of primary schools. Atmos. Environ. 2014, 82, 298-306.

22. Chen, Q.; Zheng, T.; Bassig, B.; Cheng, Y.; Leadener, B.; Lin, S.; Holford, T.; Qiu, J.; Zheng, Y.; Shi, K.; Zhu, Y.; Niu, J.; Li, Y.; Guo, H.; Hu, X.; Jin, Y. Prenatal exposure to polyaromatic hydrocarbons and birth weigh in China. Open J. Air Pollut. 2014, 3, 100-110. DOI: 10.4236/ojap.34010.

23. Quiroz, R.; Grimalt, J.O.; Fernandez, P. Toxicity assessment of polycyclic aromatic hydrocarbons in sediments from European high mountain lakes. Ecotoxicol Environ. Saf. 2010, 73, 559-1564. 
24. Czaja, A.U.; Trukhan N.; Müller U. Industrial applications of metal-organic frameworks. Chem. Soc. Rev. 2009, 5, 1284-1293.

25. Eddaoudi, M.; Kim, J.; Rosi, N.; Vodak, D.; Wachter, J.; O'Keeffe, M.; Yaghi, O.M. Systematic design of pore size and functionality in isoreticular MOFs and their application in ethane storage. Environ. Eng. Sci. 2002, 295, 469-472.

26. Corma, A.; Garcia, H.; Llabrés, I.; Xamena, F.X. Engineering metal organic frameworks for heterogeneous catalysis. Chem. Rev. 2010, 110, 4606-4655.

27. Chen, B.; Wang, X.; Zhang, Q.; Xi, X.; Cai, J.; Qi, H.; Shi, S.; Wang, J. Yuan, D.; Fang, M. Synthesis and characterization of the interpenetrated MOF-5. J. Mater. Chem. 2010, 20, 3758-3767.

28. Wang, Z.; Cohen, S.M. Postsynthetic modification of metal-organic framework. Chem. Soc. Rev. 2009, 38, 1315-1329.

29. Li, J.; Cheng, S.; Zhao, Q.; Long, P.; Dong, J. Synthesis and hydrogen-storage behavior of metal-organic framework MOF-5. Int. J. Hydrogen Energy 2009, 34, 1377-1382.

30. Dikio, E.D.; Farah, A.M. Synthesis, characterization and comparative study of copper and zinc metal organic frameworks. Chem. Sci. Trans. 2013. DOI: 10.7598/cst2013.520.

31. Tella, A.C.; Owalude, S.O. A green route approach to synthesis of Ni(II) and Zn(II) template MOFs. J. Mater. Sci. 2014. DOI: 10.1007/s108553-014-8277-1.

32. Schaur, C.; Niesner, R.; Posch, U. Polycyclic aromatic hydrocarbons in urban air particulate matter: decadal and seasonal trend, chemical degradation, and sampling artifacts. Environ. Sci. Technol. 2013, 37, 2861-2868.

33. Rasheed, M.N. Adsorption technique for the removal of organic pollutants from water and wastewater, organic pollutants - monitoring, risk and treatment. IntechOpen. 2013. DOI: $10.5772 / 54048$.

34. Abdus-Salam, N.; Itiola, A.D. Potential application of termite mound for adsorption and removal of $\mathrm{Pb}$ (II) from aqueous solutions. J. Iran. Chem. Soc. 2012, 9, 373-382.

35. Chen, X.F.; Zang, H.; Wang, X.; Lu, X.Q. Metal-organic framework MIL-53(Al) as a solidphase microextraction adsorbent for the determination of 16 polycyclic aromatic hydrocarbons in water samples by gas chromatography-tandem mass spectrometry. Analyst 2012, 137, 5411-5419.

36. Huo, S.H.; Yan, X.P. Facile magnetization of metal-organic framework MIL-101 for magnetic solid-phase extraction of polycyclic aromatic hydrocarbons in environmental water samples. Analyst 2012, 137, 3445-3451.

37. Wu, X.; Yang, C.; Ge, J. Synthesis of enzyme/metal-organic framework composites with high stability in protein denaturing solvents. Bioresour. Bioprocess. 2017, 4, 24. DOI: 10.1186/s40643-017-0154-8.

38. Mansab, S.; Rafique, U.; Noman ul Haq, N. Synthesis of Ni based metalorganicframeworks and its applications for removal of polyaromatic hydrocarbons. Int. J. Innov. Sci Res. 2015, 15, 443-451. 